\title{
The Neuroprotective Effect of Byu d Mar 25 in LPS-Induced Alzheimer's Disease Mice Model
}

\author{
Lan Liu $\mathbb{D}^{1,2,3}$ Yongcang Zhang $\mathbb{D},{ }^{1}$ Liang Tang $\mathbb{D},{ }^{4}$ Hua Zhong $\mathbb{D},{ }^{5}$ Dunzhu Danzeng $\mathbb{D},{ }^{1}$ \\ Cuiting Liang $\mathbb{D}^{1}$, and Shanling Liu $\mathbb{D}^{2,3}$ \\ ${ }^{1}$ Medical College, Tibet University, Lhasa, Tibet 850000, China \\ ${ }^{2}$ Department of Obstetrics \& Gynecology, West China Second University Hospital, Sichuan University, Chengdu, \\ Sichuan 610041, China \\ ${ }^{3}$ Key Laboratory of Birth Defects and Related Diseases of Woman and Children (Sichuan University), Ministry of Education, \\ Sichuan 610041, China \\ ${ }^{4}$ Department of Human Anatomy, Histology and Embryology, Institute of Neuroscience, Changsha Medical University, \\ Changsha 410219, China \\ ${ }^{5}$ Department of Anatomy, Chengdu University of Traditional Chinese Medicine, Chengdu, Sichuan 610041, China
}

Correspondence should be addressed to Shanling Liu; sunny630@126.com

Received 25 September 2020; Revised 2 December 2020; Accepted 8 February 2021; Published 27 February 2021

Academic Editor: XiuMin Li

Copyright ( $\odot 2021$ Lan Liu et al. This is an open access article distributed under the Creative Commons Attribution License, which permits unrestricted use, distribution, and reproduction in any medium, provided the original work is properly cited.

\begin{abstract}
Inflammatory factors play an important role in the pathogenesis of Alzheimer's disease (AD). Byu d Mar 25 (BM25) has been suggested to have protective effects in the central nervous system. However, the effect of BM25 on AD has not been determined. This study aims to investigate the neuroprotective effect of BM25 in AD. A total of $40 \mathrm{AD}$ model mice were randomly assigned to the following five groups ( $n=8$ per group): the $\mathrm{AD}+\mathrm{NS}$ group, the $\mathrm{AD}+$ donepezil group, and three $\mathrm{AD}+\mathrm{BM} 25$ groups treated with either $58.39 \mathrm{mg} / \mathrm{kg}(\mathrm{AD}+\mathrm{BM} 25-\mathrm{L}), 116.77 \mathrm{mg} / \mathrm{kg}(\mathrm{AD}+\mathrm{BM} 25-\mathrm{M})$, or $233.54 \mathrm{mg} / \mathrm{kg}$ BM25 (AD + BM25-H). The Morris water maze test was performed to assess alterations in spatial learning and memory deficits. Nissl staining was performed to detect Nissl bodies and neuronal damage. The expression of IL- $1 \beta$ and TNF- $\alpha$ was evaluated by ELISA. The protein expression of P-P38, $\mathrm{P} 38, \mathrm{P}-\mathrm{I} \kappa \mathrm{B} \alpha$, caspase $1, \mathrm{COX} 2$, and iNOS was determined by western blotting. The expression of $\mathrm{A} \beta$, p-Tau, and CD11b was measured by immunohistochemistry. The mRNA expression levels of IL- $1 \beta$, TNF- $\alpha$, COX2, and iNOS were measured by qRTPCR. Spatial memory significantly improved in the AD + BM25-M and AD + BM25-H groups compared with the AD + NS group $(p<0.05)$. The expression of $\mathrm{A} \beta$ and $\mathrm{p}$-Tau significantly decreased in the $\mathrm{AD}+\mathrm{BM} 25-\mathrm{M}$ and $\mathrm{AD}+\mathrm{BM} 25-\mathrm{H}$ groups $(p<0.05)$. The neuron density and hierarchy and number of pyramidal neurons significantly increased in the AD $+\mathrm{BM} 25-\mathrm{M}$ and $\mathrm{AD}+\mathrm{BM} 25-\mathrm{H}$ groups $(p<0.05)$. In addition, the expression levels of CD11b, IL- $1 \beta, \mathrm{TNF}-\alpha, \mathrm{COX} 2$, iNOS, caspase $1, \mathrm{p}-\mathrm{I} \kappa \mathrm{B} \alpha$, and $\mathrm{p}-\mathrm{P} 38$ significantly decreased in the $\mathrm{AD}+\mathrm{BM} 25-\mathrm{M}$ and $\mathrm{AD}+\mathrm{BM} 25-\mathrm{H}$ groups $(p<0.05)$. In conclusion, our findings suggest that $\mathrm{BM} 25$ may exert anti-inflammatory and neuroprotective effects in $\mathrm{AD}$ model mice by suppressing the activity of microglia and inhibiting the phosphorylation of $\mathrm{I} \kappa \mathrm{B} \alpha$ and $\mathrm{p} 38$ MAPK.
\end{abstract}

\section{Introduction}

Alzheimer's disease (AD) is a common neurodegenerative disease in the elderly population that causes declines in learning and memory [1-4]. The incidence of $\mathrm{AD}$ in people over the age of 65 is approximately 5\% [5]. However, the pathogenesis of sporadic AD is still not fully understood. Neuroinflammation has been suggested to play an important role in the development of $\mathrm{AD}[6,7]$. At present, the role of glial cell activation, especially microglial cells, in neuroinflammation has been widely confirmed $[8,9]$.

Byu d Mar 25 (BM25) was developed by the Tibetan Medicine Master Dima Danzeng Peng Cuo in the 18th century and is still used today for multiple neurological disorders [10]. BM25 is composed of 25 rare herbs, such as saffron, calamus, and musk. It has the functions of opening 
the orifices and relieving pain. A clinical study has shown that BM25 has positive effects on neuropathic pain, epilepsy, stroke, and multiple peripheral neuropathies and neurological disorders [11]. In addition, BM25 has been shown to attenuate neuronal and astrocyte injury by inhibiting the neuronal denaturation and astrocyte overactivation induced by D-galactose [12]. These findings may indicate a potential therapeutic role for BM25 in AD.

The pharmacological mechanism of BM25 at the molecular level has been less studied. Du et al. found that BM25 reduced the expression levels of nitric oxide (NO) and nitric oxide synthase (NOS) in the plasma of migraine rat models [11]. Liu et al. reported that BM25 inhibited the phosphorylation of NF-kB P65 in human neuroblastoma cells (SH-SY5Y) [13]. The results of network pharmacological analysis suggested that the anti-AD mechanism of BM25 might be related to the regulation of the MAPK, insulin, and mTOR signal transduction pathways; intervention in inflammation and immunity; apoptosis and autophagy; and intervention in $\mathrm{A} \beta$ expression and clearance in brain tissue [14].

However, no systematic research on the effect and mechanism of BM25 in AD has been conducted. In the present study, we aimed to illustrate the effect and mechanism of BM25 in an LPS-induced AD mouse model.

\section{Materials and Methods}

2.1. Animals and Drug Administration. This experiment followed the ethical standards of the Declaration of Helsinki as well as national and international guidelines. The research procedures were approved by the Ethics Committee of Tibet University, China (EC20190018). The LPS-induced AD mouse model was established according to our previous study [15]. A total of 40 LPS-induced AD mice were randomly divided into the following five groups:

(1) $\mathrm{AD}+$ donepezil group (donepezil $(1 \mathrm{mg} / \mathrm{ml}), 0.1 \mathrm{ml} /$ $10 \mathrm{~g})(n=8)$

(2) AD + NS group (normal saline (NS) (0.9\%), $0.1 \mathrm{ml} /$ $10 \mathrm{~g})(n=8)$

(3) $\mathrm{AD}+\mathrm{BM} 25-\mathrm{L}$ group (low dose, L) $(58.39 \mathrm{mg} / \mathrm{kg}$, $0.1 \mathrm{ml} / 10 \mathrm{~g})(n=8)$

(4) $\mathrm{AD}+\mathrm{BM} 25-\mathrm{M}$ group (medium dose, $\mathrm{M})(116.77 \mathrm{mg} /$ $\mathrm{kg}, 0.1 \mathrm{ml} / 10 \mathrm{~g})(n=8)$

(5) $\mathrm{AD}+\mathrm{BM} 25-\mathrm{H}$ group (high dose, $\mathrm{H})(233.54 \mathrm{mg} / \mathrm{kg}$, $0.1 \mathrm{ml} / 10 \mathrm{~g})(n=8)$

The dosing and duration of BM25 followed the studies conducted by Du et al.[16] and Li et al.[17]. Drug treatments were performed by lateral ventricular stereotactic injection and lasted for four weeks. The Morris water maze test was performed on the last day of treatment to assess the alterations in spatial learning and memory deficits. Nissl staining was performed to detect Nissl bodies and neuronal damage. The expression of IL- $1 \beta$ and TNF- $\alpha$ was evaluated by ELISA. The expression of P-P38, P38, P-I $\kappa \mathrm{B} \alpha$, Caspase1, COX2, and iNOS proteins was determined by western blotting. The expression of $\mathrm{A} \beta, \mathrm{p}$-Tau, and CD11b was measured by immunohistochemistry. The mRNA expression levels of IL$1 \beta$, TNF- $\alpha$, COX2, and iNOS were measured by qRT-PCR.

2.2. Morris Water Maze Test. Spatial learning and memory deficits in the five groups were evaluated by the Morris water maze on the last day of treatment. The test protocols followed a previously published study by Vorhees et al.[18]. An ANY-maze Video Tracking System (Stoelting Co., USA) was used to track and record animal movement during the trials. The swim path, escape latency, and frequency of crossing the target platform were recorded and analyzed.

2.3. Tissue Collection. The mice were anesthetized with pentasorbital sodium $(0.2 \%, 0.1 \mathrm{ml} / 10 \mathrm{~g})$ by intraperitoneal injection. The brain tissue samples $(n=8)$ from each group were stored in $10 \%$ neutral formalin, and other specimens $(n=8)$ were stored at $-80^{\circ} \mathrm{C}$ until further analysis.

2.4. Nissl Staining. Nissl bodies in the cytoplasm of surviving neurons were detected by Nissl staining (Beyotime Institute of Biotechnology, China). The number of positive cells per unit area $\left(\mathrm{mm}^{2}\right)$ at the same site in the hippocampus was detected by using Image-Pro Plus 5.1 software (Media Cybernetics, Inc., Bethesda).

2.5. Enzyme-Linked Immunosorbent Assay (ELISA). The expression levels of IL- $1 \beta$ and TNF- $\alpha$ in brain tissues were measured by ELISA with ELISA kits that were purchased from Sigma (Tokyo, Japan). The levels of IL- $1 \beta$ and TNF- $\alpha$ were detected by a microplate spectrophotometer (Multiskan MK, Finland). The measurement data are expressed as the mean \pm standard deviation (SD).

2.6. Western Blotting. The protein expression levels of $\mathrm{p}-\mathrm{p} 38$, p38, p-I $\kappa \mathrm{B} \alpha$, Caspase1, COX2, and iNOS were detected by western blotting. The total protein concentration of the brain tissues was analyzed with a BCA kit (Sigma, CA, USA). The blots were separately probed with rabbit antibodies against p-p38 (1:1000; $43 \mathrm{kDa}$, Affinity Biosciences), p38 (1:3000; $43 \mathrm{kDa}$, Affinity Biosciences), $\mathrm{p}-\mathrm{I} \kappa \mathrm{B} \alpha(1: 1000 ; 39 \mathrm{kDa}, \mathrm{Af}-$ finity Biosciences), Caspase 1 (1:1000; $45 \mathrm{kDa}$, Affinity Biosciences), COX2 (1:1000; $72 \mathrm{kDa}$, Affinity Biosciences), iNOS ( $1: 500 ; 130 \mathrm{kDa}$, Affinity Biosciences), and $\alpha$-Tubulin (1:5000; ProMab). Subsequently, the blots were probed with horseradish peroxidase- (HRP-) conjugated goat secondary antibody against rabbit IgG (1:80000; Affinity Biosciences). Quantitative analysis of the protein bands was performed with Image-Pro Plus 5.1 software (Media Cybernetics, Inc., Bethesda).

2.7. Immunohistochemistry. The tissues were thoroughly rinsed with $\mathrm{PBS}$, treated with $3 \% \mathrm{H}_{2} \mathrm{O}_{2}$ for $20 \mathrm{~min}$, and incubated with 5\% horse serum at room temperature for $1 \mathrm{~h}$. Then, the tissues were separately incubated with mouse antibody against $\mathrm{A} \beta 1-40$ (1 : 150; Affinity Biosciences), p-Tau 
(1:200; Affinity Biosciences), or CD11b (1:150; Affinity Biosciences) at $4^{\circ} \mathrm{C}$ overnight and reacted with biotinylated broad-spectrum antibody against rabbit $\operatorname{IgG}(1: 200$; Affinity Biosciences) at room temperature for $2 \mathrm{~h}$. Finally, the immunoreactive product was visualized by incubation in $0.05 \%$ DAB (Affinity Biosciences) for $3 \mathrm{~min}$. The absorbance was analyzed by Image-Pro Plus 5.1 software (Media Cybernetics, Inc., Bethesda).

2.8. $q R T-P C R$. TRIzol Reagent (Invitrogen, Grand Island, NY, USA) was used to isolate total RNA from each brain tissue sample. The RNA quantity and integrity were measured by an ultraviolet spectrophotometer (UV-9000) (Shanghai Precision Instrument Co., Ltd.). Total RNA samples were purified with DNase, and cDNA was synthesized by a SuperScript VILO ${ }^{\mathrm{TM}}$ cDNA kit (Thermo Fisher Scientific, NY, USA). qRT-PCR was performed using HieffTM qPCR SYBR ${ }^{\circledR}$ Green Master Mix (Takara Bio Inc., Dalian, China) on a LightCycler ${ }^{\circledR}$ 2.0. The Ct values were analyzed with SDS 2.0 software (PE Biosystems). The relative mRNA expression levels of IL- $1 \beta$, TNF- $\alpha$, COX2, and iNOS were analyzed using the $2^{-\Delta \Delta \mathrm{Ct}}$ method and normalized to $\beta$-actin.

2.9. Statistical Analysis. All the data are presented as the mean \pm standard deviation (mean $\pm \mathrm{SD}$ ). The significance of difference was analyzed by SPSS 22.0 followed by a $t$-test. A value of $p<0.05$ was considered statistically significant.

\section{Results}

3.1. BM25 Significantly Decreased the Expression of $A \beta$ and p-Tau and Improved Spatial Memory in the LPS-Induced AD Mouse Model

3.1.1. Results of the Morris Water Maze. As shown in Figure 1 , the mice in the $\mathrm{AD}+\mathrm{BM} 25-\mathrm{H}$ and $\mathrm{AD}+\mathrm{BM} 25-\mathrm{M}$ groups had shorter latencies and swimming distances to escape than the mice in the $\mathrm{AD}+\mathrm{NS}$ group on the visible platform tests, indicating stronger spatial learning ability in $\mathrm{AD}$ mice treated with BM25 $(p<0.05)$. In the probe trial, the mice in the $\mathrm{AD}+\mathrm{BM} 25-\mathrm{H}$ and $\mathrm{AD}+\mathrm{BM} 25-\mathrm{M}$ groups spent significantly less time traveling into the fourth quadrant, where the hidden platform was previously placed, than the mice in the $\mathrm{AD}+\mathrm{NS}$ group, which revealed better spatial memory ability in the AD mice treated with BM25 $(p<0.05)$.

3.1.2. Expression of $A \beta$ and P-Tau. Figures 2 and 3 show that the expression of $A \beta$ and $p$-Tau was significantly lower in the $\mathrm{AD}+\mathrm{BM} 25-\mathrm{H}(\mathrm{A} \beta: 1937.75 \pm 264.35$; $\mathrm{p}-\mathrm{Tau}: 394.87 \pm 36.26)$ and $\mathrm{AD}+\mathrm{BM} 25-\mathrm{M}$ groups $(\mathrm{A} \beta: 2040.46 \pm 116.74$; p-Tau: $529.98 \pm 78.53)$ than in the $\mathrm{AD}+\mathrm{NS}$ group.

\subsection{BM25 Reduced Neuronal Damage and Neuronal Loss}

3.2.1. Nissl Staining. Under a light microscope, the pyramidal neurons in the hippocampal area of the AD + BM25-
$\mathrm{M}$ and $\mathrm{AD}+\mathrm{BM} 25-\mathrm{H}$ groups were arranged in a regular order with light staining of nuclei and clear staining of the cytoplasm in the $\mathrm{AD}+\mathrm{BM} 25-\mathrm{M}$ and $\mathrm{AD}+\mathrm{BM} 25-\mathrm{H}$ groups. In contrast, the neuron density and hierarchy decreased, the number of pyramidal neurons decreased, the neuron arrangement was disordered, the cell spacing increased, and neurons were significantly lost in the $\mathrm{AD}+\mathrm{NS}$ group (Figure 4).

3.2.2. Expression of the Caspase 1 Protein. As shown in Figure 5, the relative expression of the caspase 1 protein was significantly lower in the $\mathrm{AD}+\mathrm{BM} 25-\mathrm{H}(0.081 \pm 0.024)$ and $\mathrm{AD}+\mathrm{BM} 25-\mathrm{M}$ groups $(0.140 \pm 0.014)$ than in the $\mathrm{AD}+\mathrm{NS}$ group $(0.400 \pm 0.102)(p<0.05)$.

\subsection{BM25 Inhibited the Activity of Microglia and Decreased the Expression Levels of IL-1 $\beta, T N F-\alpha, C O X 2$, and iNOS}

3.3.1. Activity of Microglia. As shown in Figure 6, the microglial cells in the hippocampus of the $\mathrm{AD}+\mathrm{BM} 25-\mathrm{H}$ and $A D+B M 25-M$ groups were small, rod-shaped, and thin and had few branches. The microglial cells in the AD + NS group were branched, and the cell bodies became larger and rounder with more branches. The number of activated microglial cells (CD11b-positive cells) in the $\mathrm{AD}+\mathrm{NS}$ group was significantly increased compared with those in the $\mathrm{AD}+\mathrm{BM} 25-\mathrm{H}(1216.63 \pm 217.91)$ and $\mathrm{AD}+\mathrm{BM} 25-\mathrm{M}$ groups $(1404.20 \pm 120.01)(p<0.05)$.

3.3.2. Expression of Proinflammatory Cytokines. The relative mRNA expression levels of IL- $1 \beta$, TNF- $\alpha$, COX2, and iNOS in the $\mathrm{AD}+\mathrm{BM} 25-\mathrm{H}$ and $\mathrm{AD}+\mathrm{BM} 25-\mathrm{M}$ groups were found to be significantly lower than those in the $\mathrm{AD}+\mathrm{NS}$ group $(p<0.05)$ (Figure 7). The ELISA results showed that the protein expression of IL- $1 \beta$ and TNF- $\alpha$ in the brain was significantly decreased in the $\mathrm{AD}+\mathrm{BM} 25-\mathrm{H}$ (IL-1 $\beta$ : $192.64 \pm 22.49$; TNF- $\alpha: 445.58 \pm 33.73)$ and AD + BM25-M (IL-1 $\beta: 274.22 \pm 56.87$; TNF- $\alpha: \quad 461.18 \pm 100.14$ ) groups compared with the $\mathrm{AD}+\mathrm{NS}$ group (IL-1 $\beta: 505.69 \pm 43.33$; TNF- $\alpha$ : $714.65 \pm 23.00)(p<0.05)$ (Figure 8). In addition, western blotting revealed that the number of COX2-and iNOS-positive dots (relative content ratio) in the $\mathrm{AD}+\mathrm{BM} 25-\mathrm{M}$ (COX2: $0.096 \pm 0.019$; iNOS: $0.182 \pm 0.020$ ) and $\mathrm{AD}+\mathrm{BM} 25-\mathrm{H}$ groups (COX2: $0.063 \pm 0.025$; iNOS: $0.108 \pm 0.011)$ was significantly decreased compared with that in the $\mathrm{AD}+\mathrm{NS}$ group (COX2: $0.375 \pm 0.014$; iNOS: $0.548 \pm 0.126)(p<0.05)$ (Figure 5).

3.4. BM25 Suppressed the Phosphorylation of $I \kappa B \alpha$ and $p 38$ $M A P K$. Western blotting showed that the relative expression levels of $\mathrm{p}-\mathrm{I} \kappa \mathrm{B} \alpha$ and $\mathrm{p}-\mathrm{P} 38$ MAPK were significantly lower in the $\mathrm{AD}+\mathrm{BM} 25-\mathrm{M}(\mathrm{p}-\mathrm{I} \kappa \mathrm{B} \alpha: 0.353 \pm 0.012$; p-p38: $0.152 \pm 0.022)$ and $\mathrm{AD}+\mathrm{BM} 25-\mathrm{H}$ groups $(\mathrm{p}-\mathrm{I} \kappa \mathrm{B} \alpha$ : $0.229 \pm 0.015 ; \mathrm{p}-\mathrm{p} 38: 0.109 \pm 0.019)$ than in the $\mathrm{AD}+\mathrm{NS}$ group $(\mathrm{p}-\mathrm{I} \kappa \mathrm{B} \alpha: \quad 0.758 \pm 0.021 ; \quad \mathrm{p}-\mathrm{p} 38: 0.577 \pm 0.024)$ $(p<0.05)$. Thus, BM25 can inhibit the phosphorylation of $\mathrm{I} \kappa \mathrm{B} \alpha$ and $\mathrm{p} 38$ MAPK (Figure 5). 


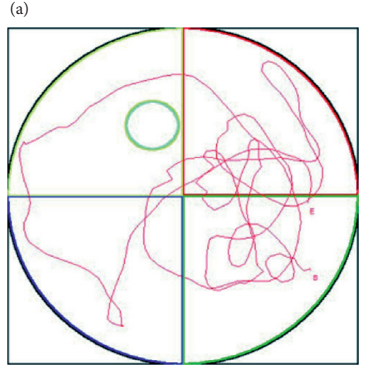

$\mathrm{AD}+\mathrm{NS}$

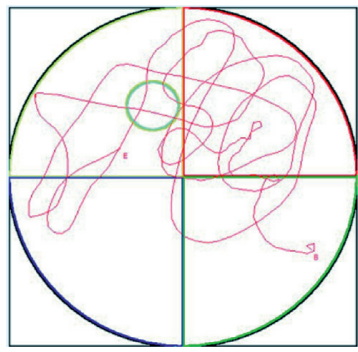

$\mathrm{AD}+\mathrm{BM} 25-\mathrm{L}$

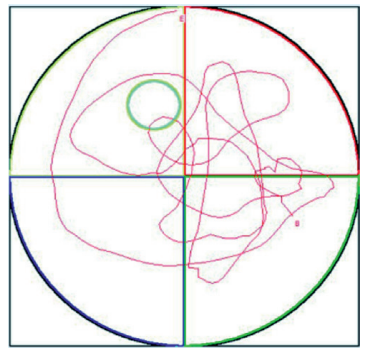

$\mathrm{AD}+\mathrm{BM} 25-\mathrm{H}$

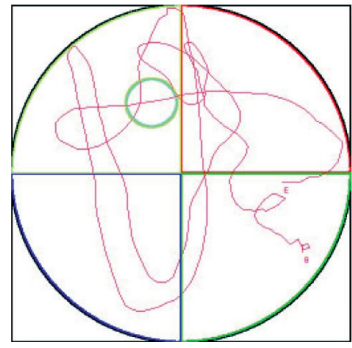

$\mathrm{AD}+$ donepezil

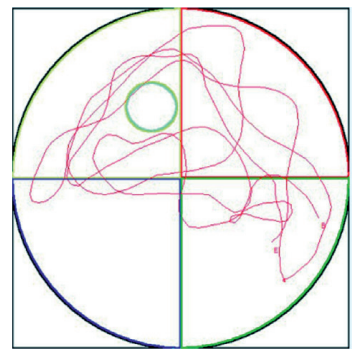

$\mathrm{AD}+\mathrm{BM} 25-\mathrm{M}$

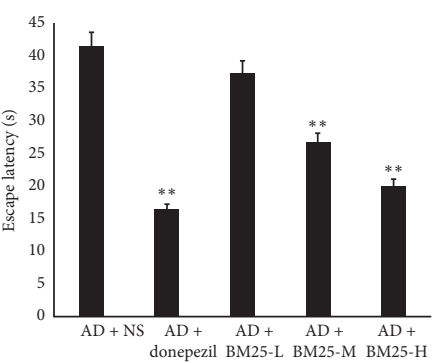

(b)

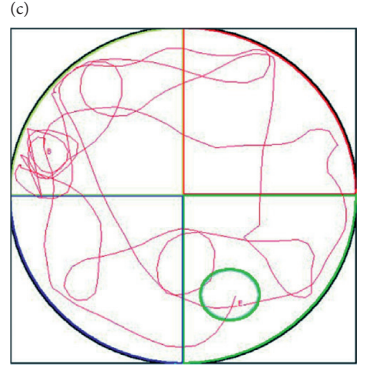

$\mathrm{AD}+\mathrm{NS}$

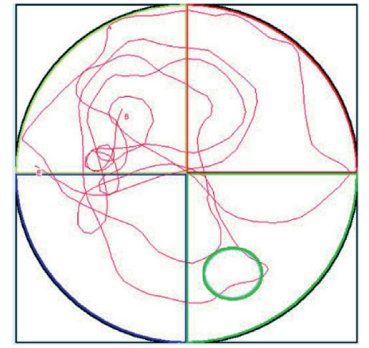

AD + BM25-L

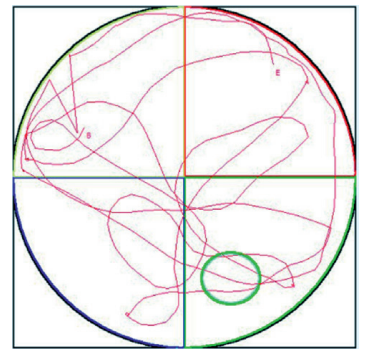

$\mathrm{AD}+\mathrm{BM} 25-\mathrm{M}$

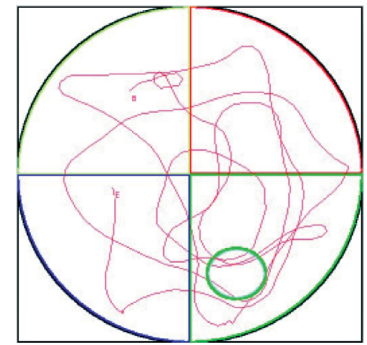

$\mathrm{AD}+$ donepezil

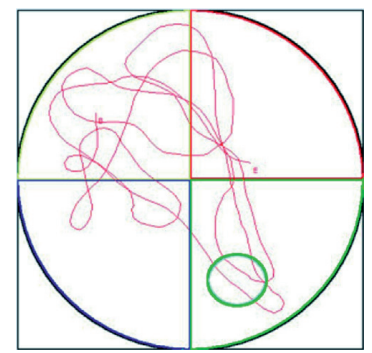

$\mathrm{AD}+\mathrm{BM} 25-\mathrm{M}$

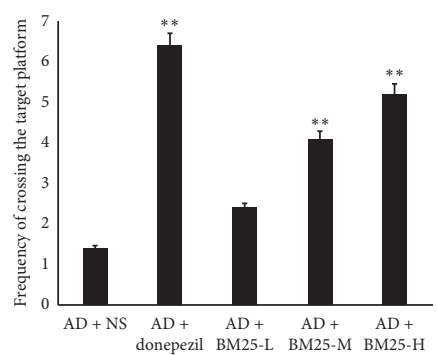

(d)

Figure 1: Testing of spatial learning and memory in $\mathrm{AD}+\mathrm{NS}, \mathrm{AD}+$ donepezil, and $\mathrm{AD}+\mathrm{BM} 25$ groups by Morris water maze. (a) The swimming trajectory of mice in the $\mathrm{AD}+\mathrm{NS}, \mathrm{AD}+$ donepezil, and $\mathrm{AD}+\mathrm{BM} 25$ groups. (b) Escape latency in $\mathrm{AD}+\mathrm{NS}, \mathrm{AD}+\mathrm{donepezil}$, and $\mathrm{AD}+\mathrm{BM} 25$ groups. (c) Probe trial; the travel trajectory of mice in the AD + NS, AD + donepezil, and AD + BM25 groups. (d) The frequency of crossing the target platform in $\mathrm{AD}+\mathrm{NS}, \mathrm{AD}+$ donepezil, and $\mathrm{AD}+\mathrm{BM} 25$ groups. A significant difference in escape latency in the $\mathrm{AD}+\mathrm{BM} 25$ group rather than that in the $\mathrm{AD}+\mathrm{NS}$ group was detected $\left({ }^{*} p<0.05\right)$. A more significant frequency in crossing the target platform in $\mathrm{AD}+\mathrm{BM} 25$ groups than that in the $\mathrm{AD}+\mathrm{NS}$ group was detected $\left({ }^{*} * p<0.05\right)$. Data are expressed as the mean \pm standard error of the mean (SEM). ( $n=8$ /group in the $\mathrm{AD}+\mathrm{BM} 25$ group; $n=8$ /group in the $\mathrm{AD}+$ donepezil group; $n=8 /$ group in the $\mathrm{AD}+\mathrm{NS}$ group). BM25: Byu d Mar 25; AD: Alzheimer's disease; NS: normal saline.

\section{Discussion}

The etiology of AD is complex. Neuroinflammation is one of the main factors involved in the occurrence and development of $\mathrm{AD}$ and one of the important therapeutic targets for $\mathrm{AD}$ [19]. At present, the role of glial cells, especially microglia, in neuroinflammation has become a hotspot of research. Studies have shown that the inflammatory response induced by microglial activation is one of the pathogeneses of AD [20,21]. Microglia can be activated and then produce a large number of proinflammatory factors, such as interleukin- $1 \beta$ (IL- $1 \beta$ ) and tumor necrosis factor- $\alpha$ (TNF- $\alpha$ ) [22]. Research has shown that IL-1 $\beta$ can be induced by the beta amyloid precursor (beta amyloid, $A \beta$ ) and cause $A \beta$ deposition and Tau protein phosphorylation by reducing the expression of genes related to $A \beta$ clearance [23]. Additionally, $A \beta$ can bind to a specific receptor, activate microglia, and promote the release a large number of inflammatory factors and toxic substances [24]. Furthermore, activated microglial cells can express large quantities of iNOS and produce excess NO, which damages neurons by inhibiting cytochrome oxidase in the mitochondria of neurons [25]. Cox-2 is an inducible isoenzyme that is expressed in small amounts in microglia at rest. Under the action of proinflammatory molecules such as LPS, intracellular COX-2 mRNA levels increase, microglia are activated, and inflammatory mediators such as TNF- $\alpha$ and IL- 6 are released [26].

BM25 is mainly used to invigorate the circulation of blood and to remove blood stasis. Chen et al. showed that calamus reduced the expression of the aquaporin- 4 gene in glial cells [27]. Shi et al. reported that musk extract had a significant protective effect against the inflammatory damage of nerve cells caused by LPS, possibly by reducing the secretion of IL- 6 by glial cells [28]. Our results confirmed that BM25 can significantly reduce the production of TNF- $\alpha$, IL- $1 \beta$, iNOS, COX- $2, A \beta$, and p-Tau and improve spatial memory, suggesting that BM25 may improve 


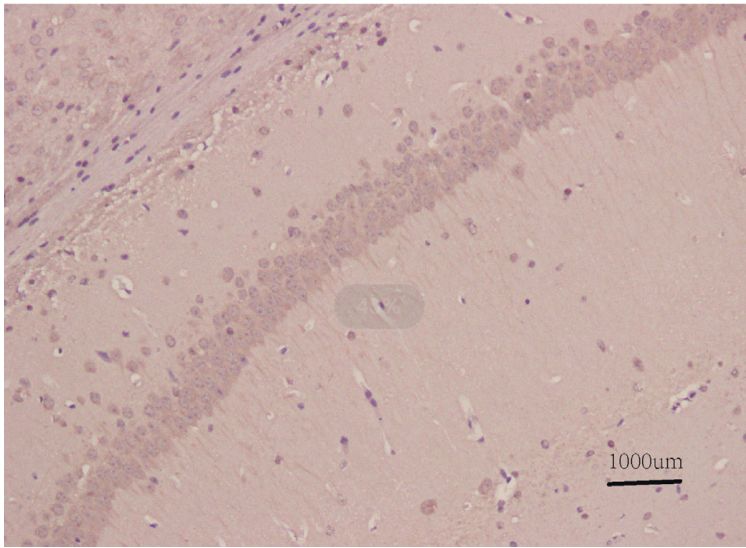

$\mathrm{AD}+\mathrm{NS}$

(a)

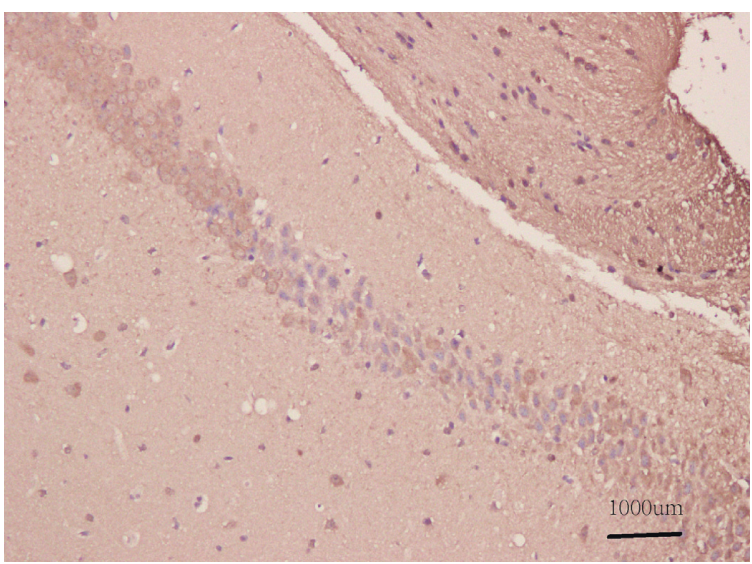

$\mathrm{AD}+\mathrm{BM} 25-\mathrm{L}$

(c)

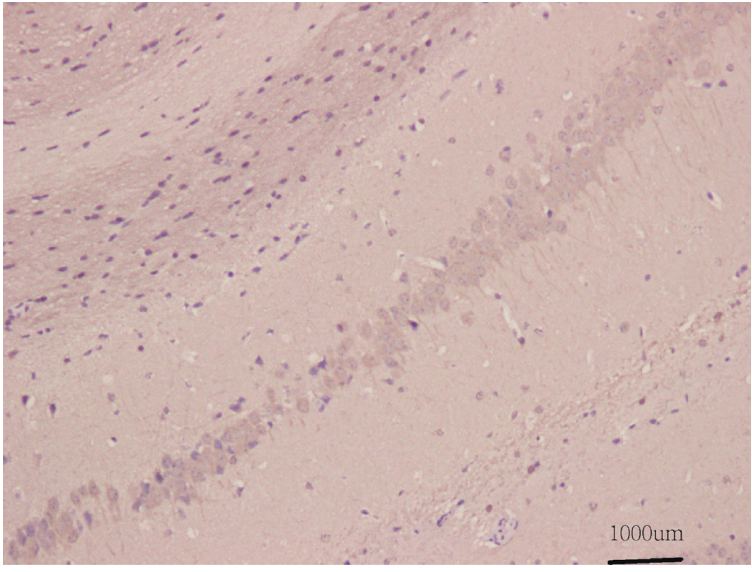

$\mathrm{AD}+\mathrm{BM} 25-\mathrm{H}$

(e)

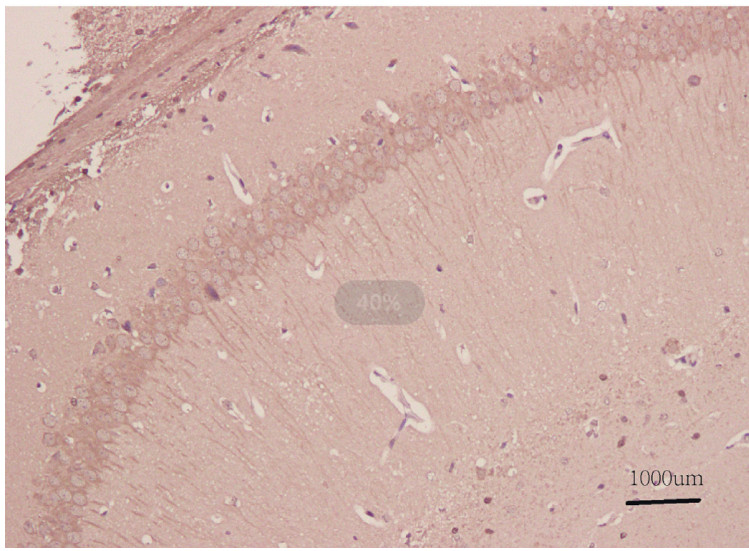

$\mathrm{AD}+$ donepezil

(b)

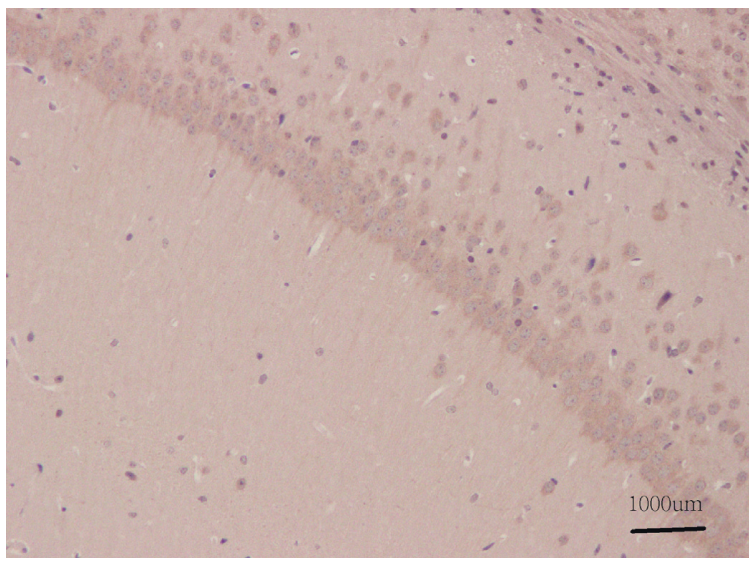

$\mathrm{AD}+\mathrm{BM} 25-\mathrm{M}$

(d)

$\mathrm{A} \beta$

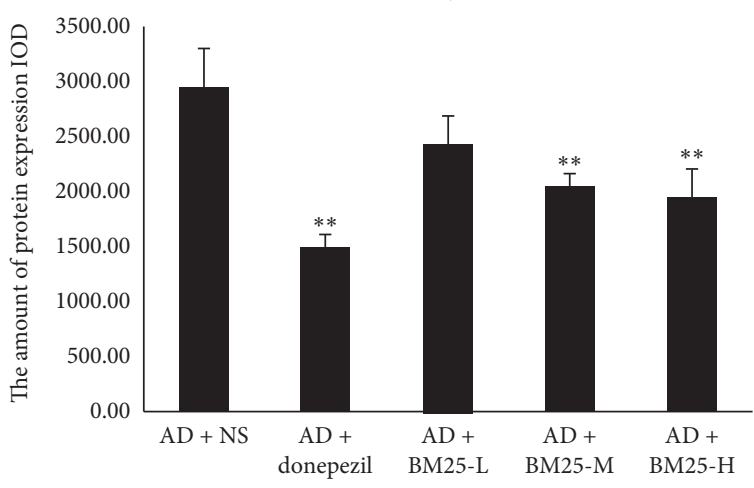

(f)

Figure 2: Light microscopic images show the distribution of $\mathrm{A} \beta$ immunolabeling across the brain of $\mathrm{AD}+\mathrm{NS}, \mathrm{AD}+$ donepezil, and $\mathrm{AD}+\mathrm{BM} 25$ groups. (a) The distribution of $\mathrm{A} \beta$ immunolabeling in the $\mathrm{AD}+\mathrm{NS}$ group. (b) The distribution of $\mathrm{A} \beta$ immunolabeling in the $\mathrm{AD}+\mathrm{donepezil}$ group. (c) The distribution of $\mathrm{A} \beta$ immunolabeling in $\mathrm{AD}+\mathrm{BM} 25-\mathrm{L}$. (d) The distribution of $\mathrm{A} \beta$ immunolabeling in $\mathrm{AD}+\mathrm{BM} 25-\mathrm{M}$. (e) The distribution of $\mathrm{A} \beta$ immunolabeling in $\mathrm{AD}+\mathrm{BM} 25-\mathrm{H}$. (f) The comparison of $\mathrm{A} \beta$ in $\mathrm{AD}+\mathrm{NS}, \mathrm{AD}+$ donepezil, and $\mathrm{AD}+\mathrm{BM} 25$ groups. The images revealed that the $\mathrm{A} \beta$ was highly expressed in the $\mathrm{AD}+\mathrm{NS}$ group compared with the $\mathrm{AD}+\mathrm{BM} 25$ groups. Data are expressed as the mean \pm standard error of the mean (SEM) ( $n=8$ /group in the $\mathrm{AD}+\mathrm{BM} 25$ group; $n=8$ /group in the $\mathrm{AD}+$ donepezil group; $n=8 /$ group in the $\mathrm{AD}+\mathrm{NS}$ group). BM25: Byu d Mar 25; AD: Alzheimer disease; NS: normal saline. 


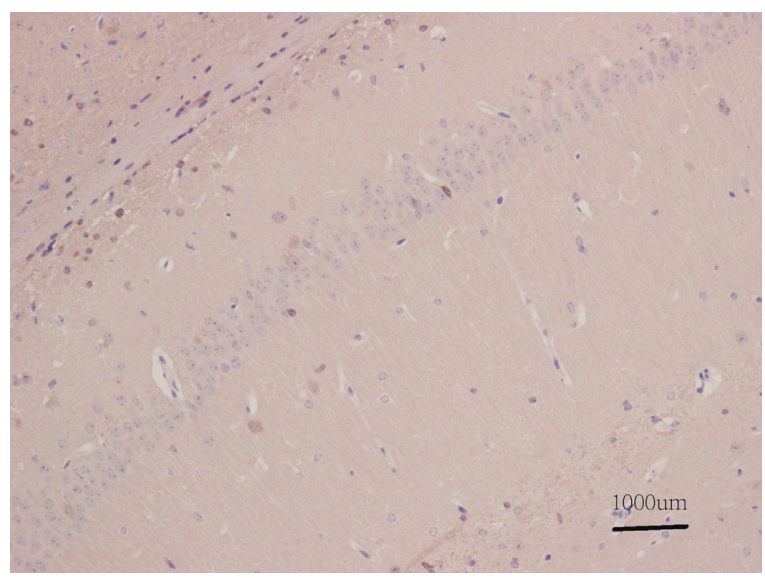

$\mathrm{AD}+\mathrm{NS}$

(a)

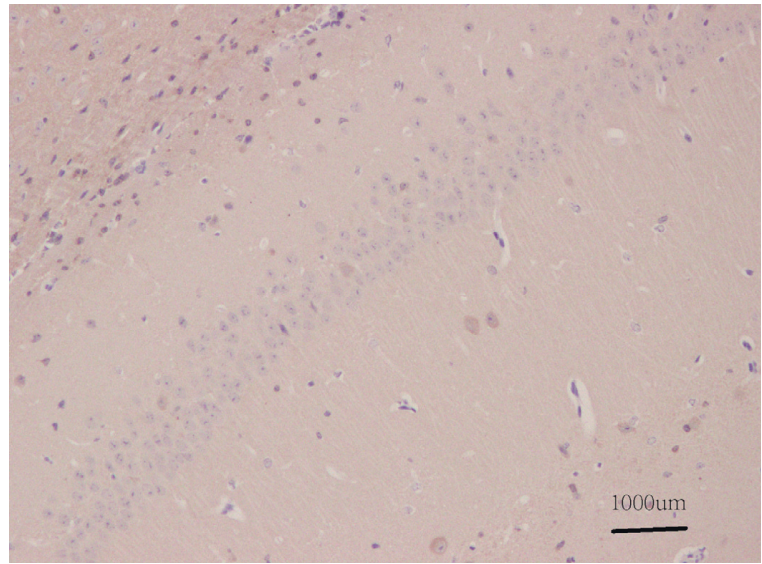

$\mathrm{AD}+\mathrm{BM} 25-\mathrm{L}$

(c)

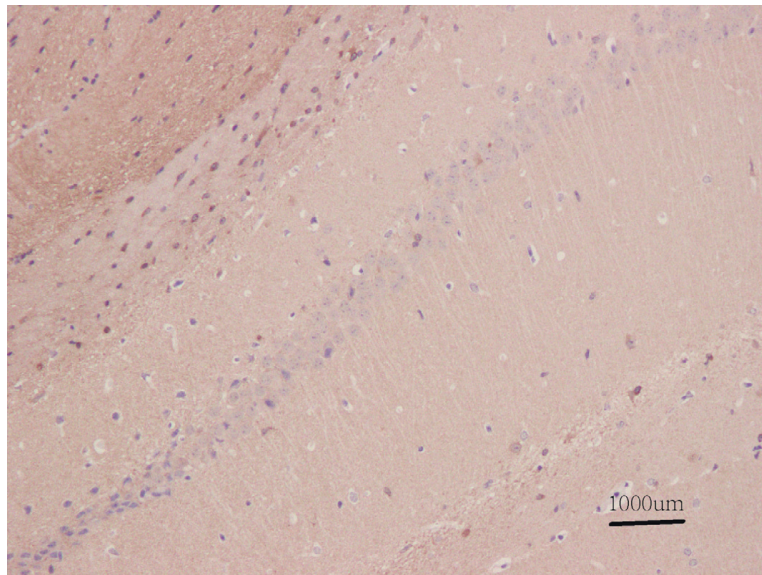

$\mathrm{AD}+\mathrm{BM} 25-\mathrm{H}$

(e)

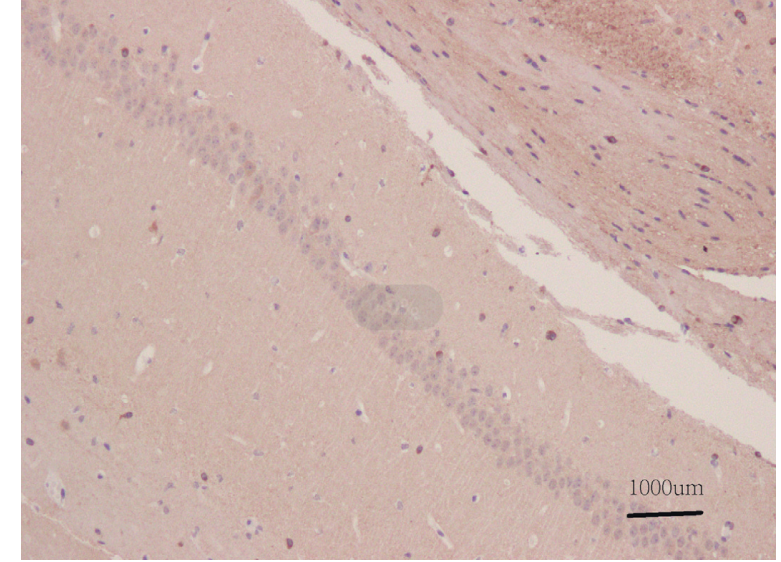

$\mathrm{AD}+$ donepezil

(b)

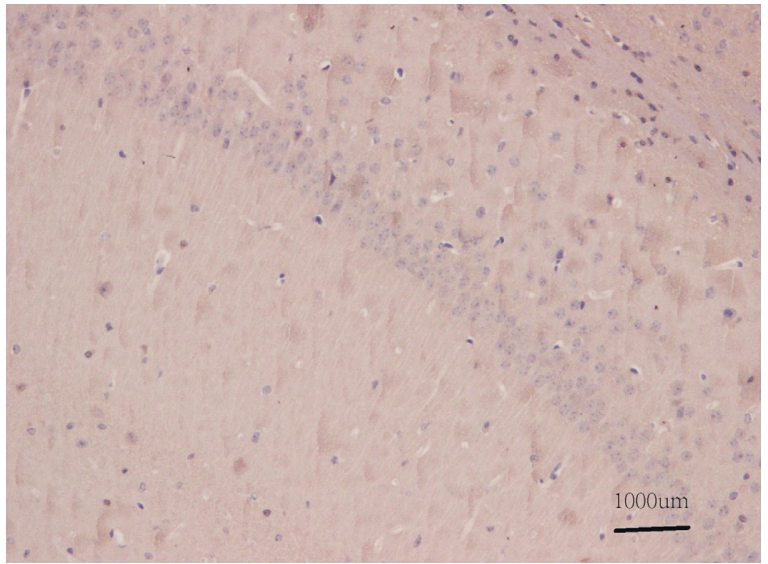

$\mathrm{AD}+\mathrm{BM} 25-\mathrm{M}$

(d)

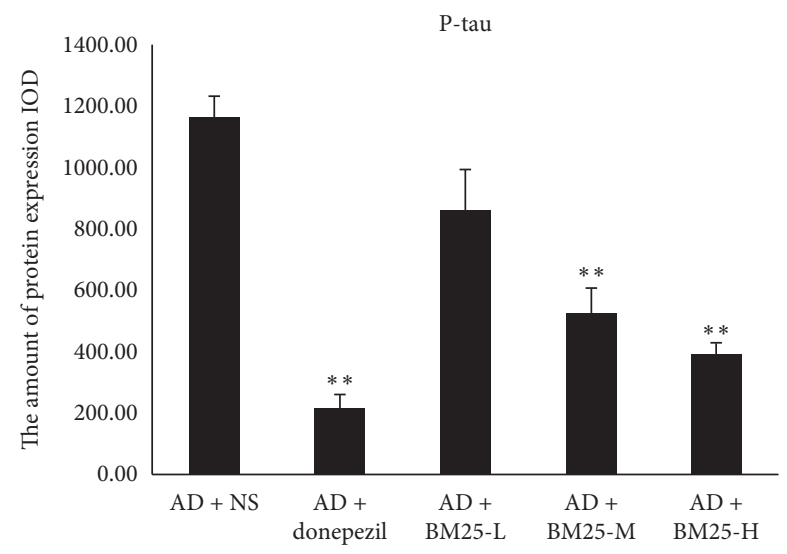

(f)

FIGURE 3: Light microscopic images show the distribution of p-Tau immunolabeling across the brain of AD + NS, AD + donepezil, and $\mathrm{AD}+\mathrm{BM} 25$ groups. (a) The distribution of $\mathrm{p}$-Tau immunolabeling in the AD + NS group. (b) The distribution of p-Tau immunolabeling in the $\mathrm{AD}+$ donepezil group. (c) The distribution of $\mathrm{p}$-Tau immunolabeling in $\mathrm{AD}+\mathrm{BM} 25-\mathrm{L}$ group. (d) The distribution of $\mathrm{p}$-Tau immunolabeling in AD + BM25-M. (e) The distribution of $p$-Tau immunolabeling in AD + BM25-H. (f) The comparison of $p$-Tau in $\mathrm{AD}+\mathrm{NS}, \mathrm{AD}+$ donepezil, and $\mathrm{AD}+\mathrm{BM} 25$ groups. The images revealed that the $\mathrm{p}$-Tau was highly expressed in the $\mathrm{AD}+\mathrm{NS}$ group compared with the AD + BM25 groups. Data are expressed as the mean \pm standard error of the mean $(\mathrm{SEM})(n=8 /$ group in the AD $+\mathrm{BM} 25$ group; $n=8$ /group in the $\mathrm{AD}+$ donepezil group; $n=8$ /group in the $\mathrm{AD}+\mathrm{NS}$ group). BM25: Byu d Mar 25; AD: Alzheimer's disease; NS: normal saline. 


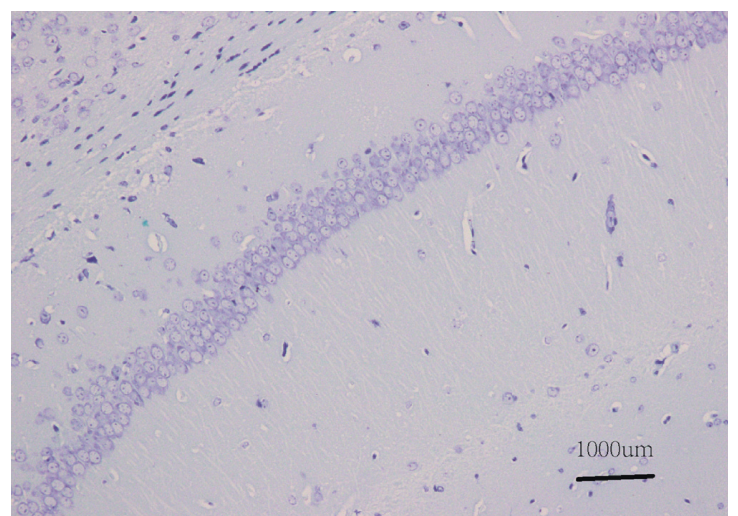

$\mathrm{AD}+\mathrm{NS}$

(a)

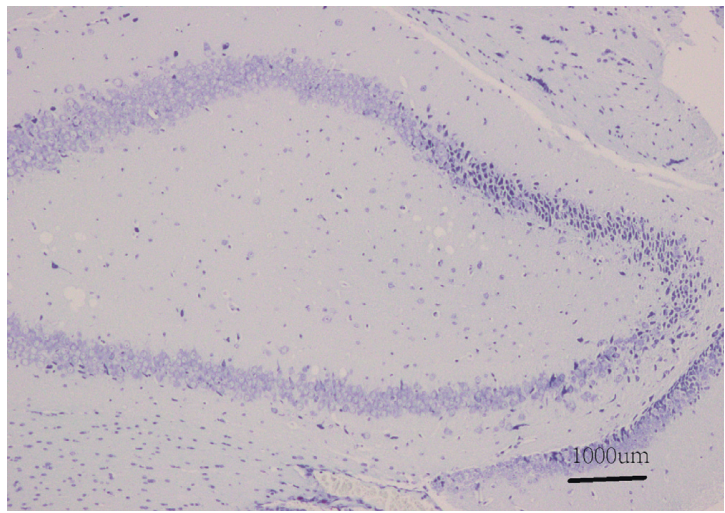

$\mathrm{AD}+\mathrm{BM} 25-\mathrm{L}$

(c)

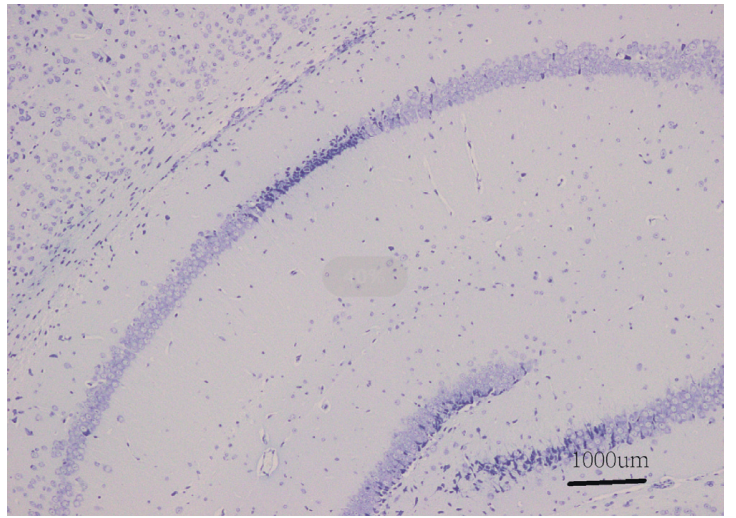

$\mathrm{AD}+\mathrm{BM} 25-\mathrm{H}$

(e)

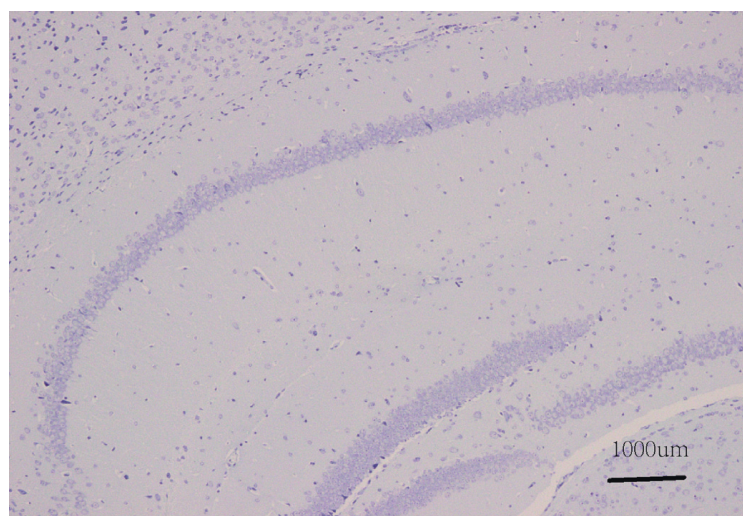

$\mathrm{AD}+$ donepezil

(b)

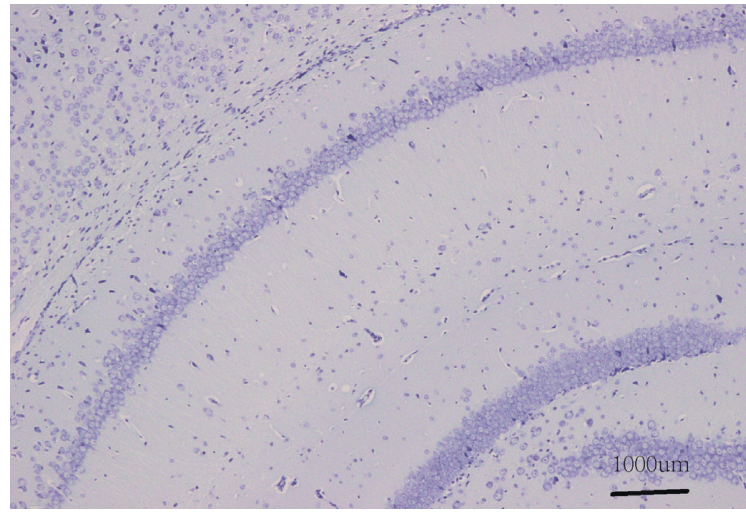

$\mathrm{AD}+\mathrm{BM} 25-\mathrm{M}$

(d)

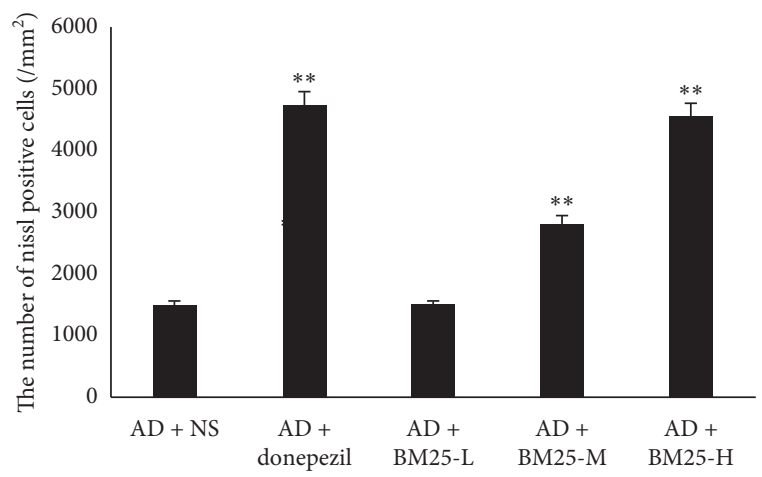

(f)

Figure 4: The results of Nissl staining. (a) Nissl staining in the AD + NS group. (b) Nissl staining in the AD + donepezil group. (c) Nissl staining in the $\mathrm{AD}+\mathrm{BM} 25-\mathrm{L}$ group. (d) Nissl staining in the $\mathrm{AD}+\mathrm{BM} 25-\mathrm{M}$ group. (e) Nissl staining in the $\mathrm{AD}+\mathrm{BM} 25-\mathrm{H}$ group. (f) The comparison of the number of pyramidal neurons in $\mathrm{AD}+\mathrm{NS}, \mathrm{AD}+$ donepezil, and $\mathrm{AD}+\mathrm{BM} 25$ groups. A significant difference of the neuron density and hierarchy and number of pyramidal neurons was observed between the AD + BM25 and AD + NS groups. Data are expressed as the mean \pm standard error of the mean (SEM) ( $n=8$ /group in $\mathrm{AD}+\mathrm{BM} 25$ group; $n=8$ /group in the $\mathrm{AD}+$ donepezil group; $n=8$ /group in the AD + NS group). BM25: Byu d Mar 25; AD: Alzheimer's disease; NS: normal saline.

AD-like symptoms by inhibiting the activation of microglia, reducing the expression of proinflammatory cytokines and altering $\mathrm{A} \beta$ and $\mathrm{p}$-Tau expression and clearance in brain tissue.
The NF- $\kappa \mathrm{B}$ pathway plays an important role in LPSinduced microglia [29]. Liu et al. showed that LPS activates the NF- $\kappa \mathrm{B}$ signaling pathway in microglia by binding to TLR4 and activating the expression of chemokines, 


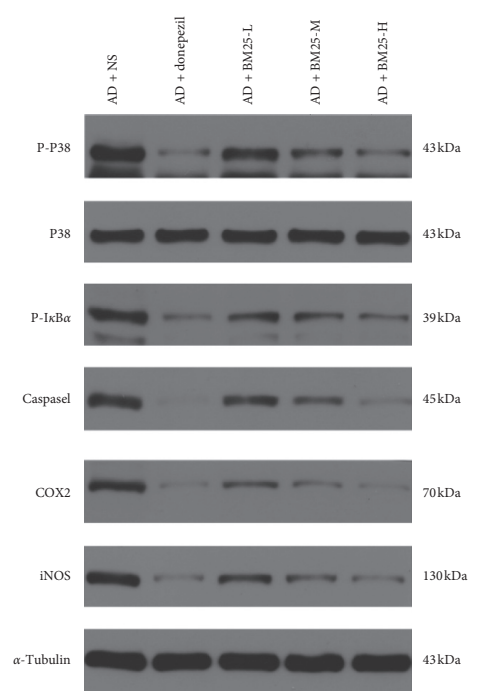

(a)
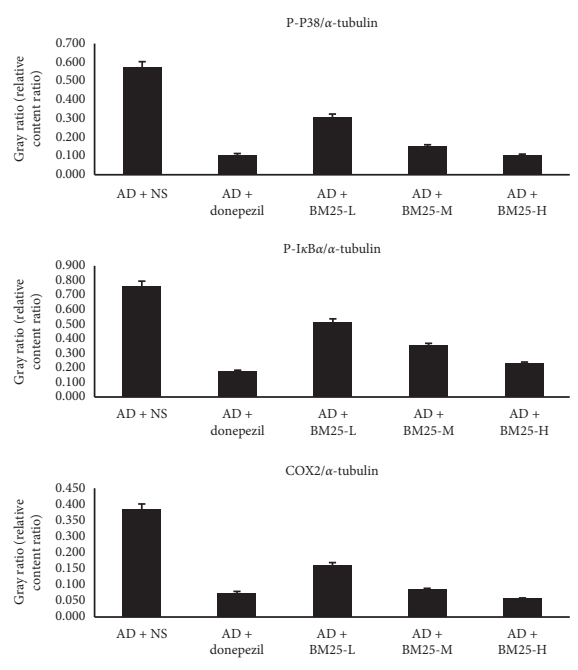

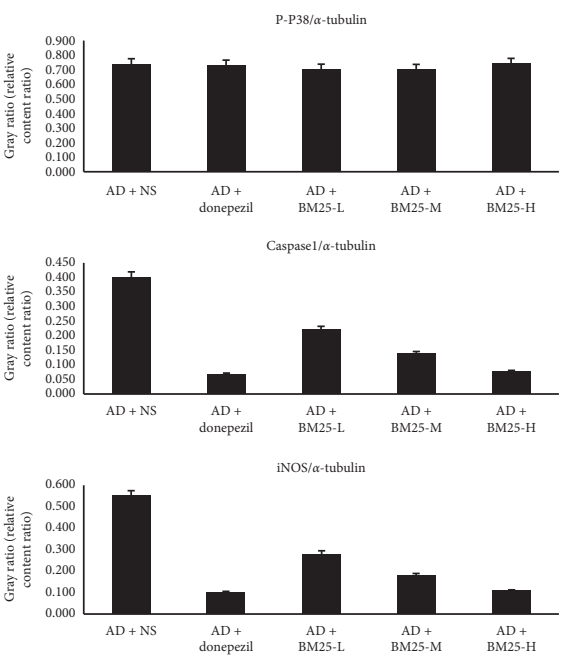

(b)

Figure 5: The expression levels of p-P38, P38, p-I $\kappa \mathrm{B} \alpha$, caspase 1, COX2, and iNOS proteins in AD + NS, AD + donepezil, and AD + BM25 groups. Quantitative summaries of the protein levels relative to $\alpha$-tubulin as an internal control, expressed as a percentage of $\alpha$-tubulin optical density (o.d.) for the groups ( $n=8$ /group). Statistical results (Kruskal-Wallis nonparametric test with Dunn's multiple post-hoc comparison) were shown in the bar graphs, with "**” indicating significant intergroup difference. Data are expressed as the mean \pm standard error of the mean (SEM) ( $n=8$ /group). (a) Expression levels of p-P38 in AD + NS, AD + donepezil, and AD + BM25 groups; (b) expression levels of $\mathrm{P} 38$ in $\mathrm{AD}+\mathrm{NS}, \mathrm{AD}+$ donepezil, and $\mathrm{AD}+\mathrm{BM} 25$ groups; (c) expression levels of $\mathrm{p}-\mathrm{I} \kappa \mathrm{B} \alpha$ in $\mathrm{AD}+\mathrm{NS}, \mathrm{AD}+\mathrm{donepezil}$, and $\mathrm{AD}+\mathrm{BM} 25$ groups; (d) expression levels of Caspase1 in AD + NS, AD + donepezil, and AD + BM25 groups; (e) expression levels of COX2 in $\mathrm{AD}+\mathrm{NS}, \mathrm{AD}+$ donepezil, and AD + BM25 groups; (f) expression levels of iNOS in AD + NS, AD + donepezil, and AD + BM25 groups. BM25: Byu d Mar 25; AD: Alzheimer's disease; NS: normal saline.

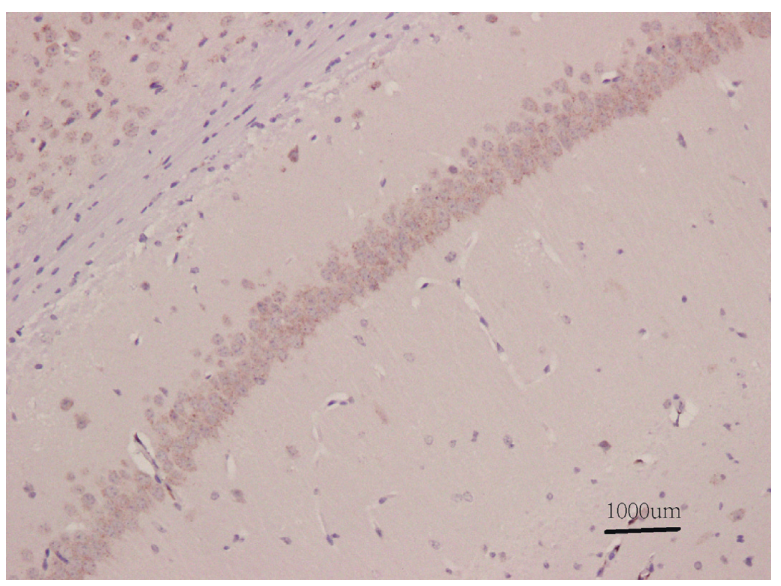

$\mathrm{AD}+\mathrm{NS}$

(a)

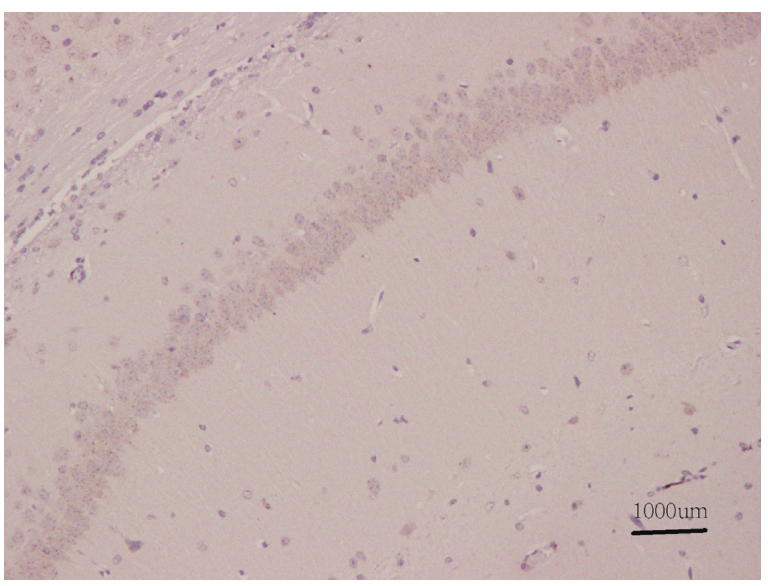

$\mathrm{AD}+$ donepezil

(b)

FIgure 6: Continued. 


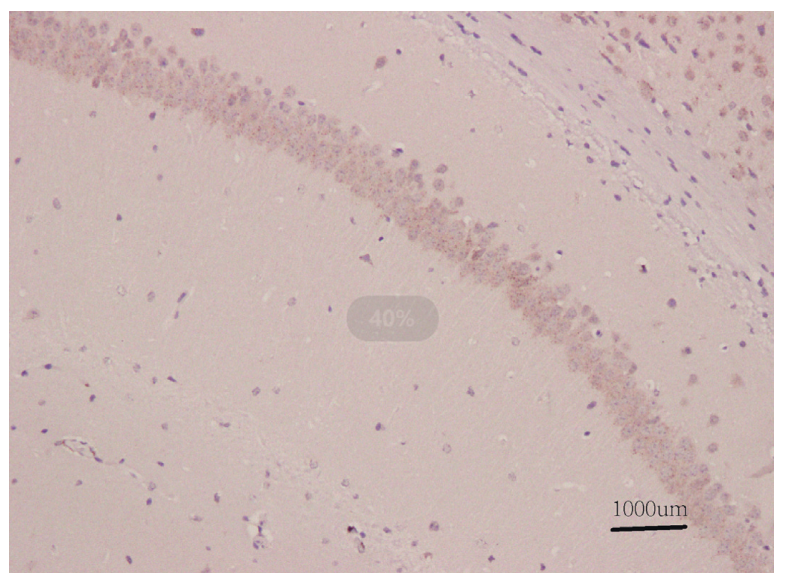

$\mathrm{AD}+\mathrm{BM} 25-\mathrm{L}$

(c)

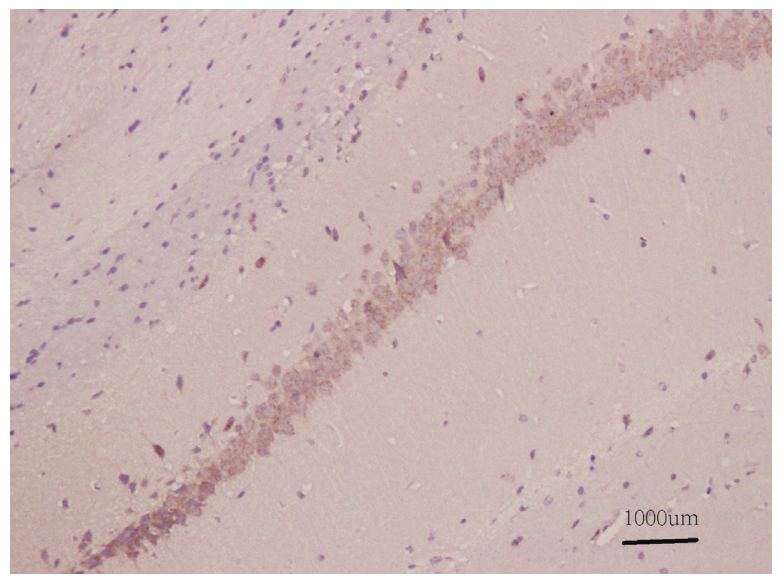

$\mathrm{AD}+\mathrm{BM} 25-\mathrm{H}$

(e)

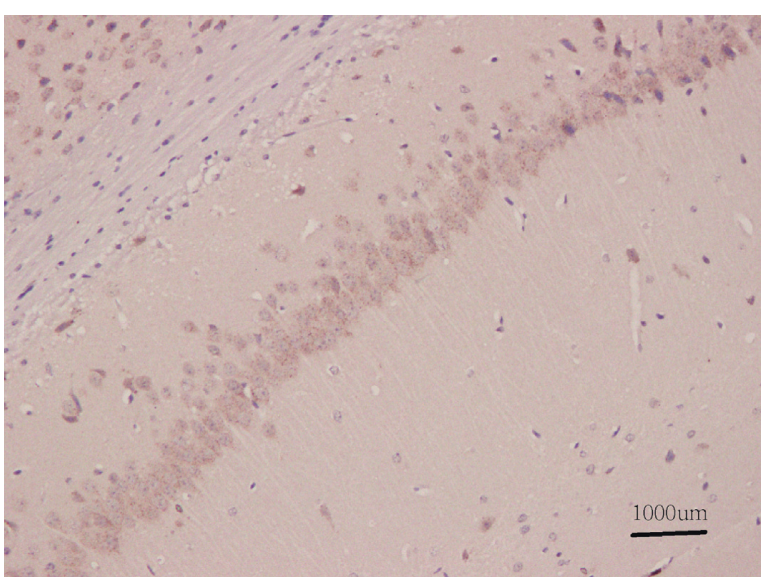

$\mathrm{AD}+\mathrm{BM} 25-\mathrm{M}$

(d)

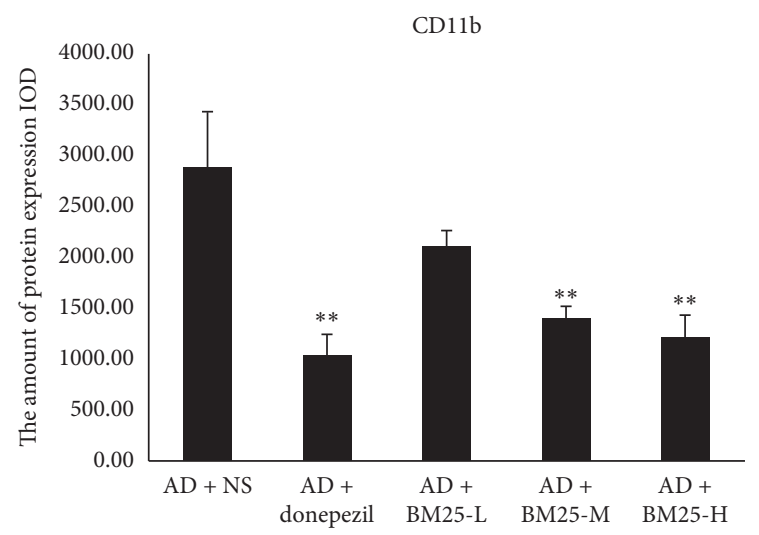

(f)

FIgURE 6: Light microscopic images show the distribution of CD11b immunolabeling across the brain of AD $+\mathrm{NS}$, AD + donepezil, and $\mathrm{AD}+\mathrm{BM} 25$ groups. (a) The distribution of CD11b immunolabeling in the $\mathrm{AD}+\mathrm{NS}$ group. (b) The distribution of CD11b immunolabeling in the $\mathrm{AD}+$ donepezil group. (c) The distribution of $\mathrm{CD} 11 \mathrm{~b}$ immunolabeling in $\mathrm{AD}+\mathrm{BM} 25-\mathrm{L}$ group. (d) The distribution of CD11b immunolabeling in AD + BM25-M. (e) The distribution of CD11b immunolabeling in AD + BM25-H. (f) The comparison of p-Tau in $\mathrm{AD}+\mathrm{NS}, \mathrm{AD}+$ donepezil, and $\mathrm{AD}+\mathrm{BM} 25$ groups. The images revealed that the $\mathrm{CD} 11 \mathrm{~b}$ was highly expressed in the $\mathrm{AD}+\mathrm{NS}$ group compared with AD + BM25 groups. Data are expressed as the mean \pm standard error of the mean (SEM) ( $n=8 /$ group in the AD $+\mathrm{BM} 25$ group; $n=8$ /group in the $\mathrm{AD}+$ donepezil group; $n=8$ /group in the $\mathrm{AD}+\mathrm{NS}$ group). BM25: Byu d Mar 25; AD: Alzheimer's disease; NS: normal saline.

proinflammatory cytokines and other genes [30]. The $\mathrm{I} \kappa \mathrm{B}$ family includes $\mathrm{I} \kappa \mathrm{B} \alpha, \mathrm{I} \kappa \mathrm{B} \beta$, and $\mathrm{I} \kappa \mathrm{B} \varepsilon$. I $\kappa \mathrm{B} \alpha$ is the most important inhibitor of NF- $\kappa \mathrm{B}$. When stimulated by an external signal, the $\mathrm{I} \kappa \mathrm{B}$ kinase $(\mathrm{IKK})$ complex is activated. Activated IKK phosphorylates IKK $\alpha$ and IKK $\beta$, which subsequently bind to ubiquitin ligases. $\mathrm{I} \kappa \mathrm{B} \alpha$ is ubiquitinated and degraded by the proteasome, leading to NF- $\kappa \mathrm{B}$ activation $[31,32]$. Thus, the phosphorylation of $I \kappa B$ is essential for NF- $\kappa \mathrm{B}$ activation. Currently, NF- $\kappa \mathrm{B}$ target genes include cytokines and inflammatory mediators (such as TNF- $\alpha$, IL-6, IL-1, and iNOS). Excessive activation of NF- $\kappa$ B leads to the production of a large number of inflammatory cytokines, which aggravates the inflammatory response. In the present study, the phosphorylation of $\mathrm{I} \kappa \mathrm{B} \alpha$ was detected by western blotting, and the results showed that BM25 significantly reduced the phosphorylation of $\mathrm{I} \kappa \mathrm{B} \alpha$, which indicated that BM25 may act as an anti-inflammatory agent by suppressing the phosphorylation of $\mathrm{I} \kappa \mathrm{B} \alpha$ and inhibiting the expression of cytokines and inflammatory mediators (such as TNF- $\alpha$, IL$1 \beta$, iNOS, and COX-2).

In addition to the NF- $\kappa \mathrm{B}$ signaling pathway, MAPK signaling plays an important role in the expression of inflammation-related factors after microglial activation. Youssef et al. showed that LPS can quickly activate p38, ERK, and JNK signaling in microglia [33]. Other molecules, such as ATP, thrombin, and TNF- $\alpha$, also activate the MAPK signaling pathway, causing microglial activation [34]. Mitogen-activated protein kinases (MAPKs) are a type of 


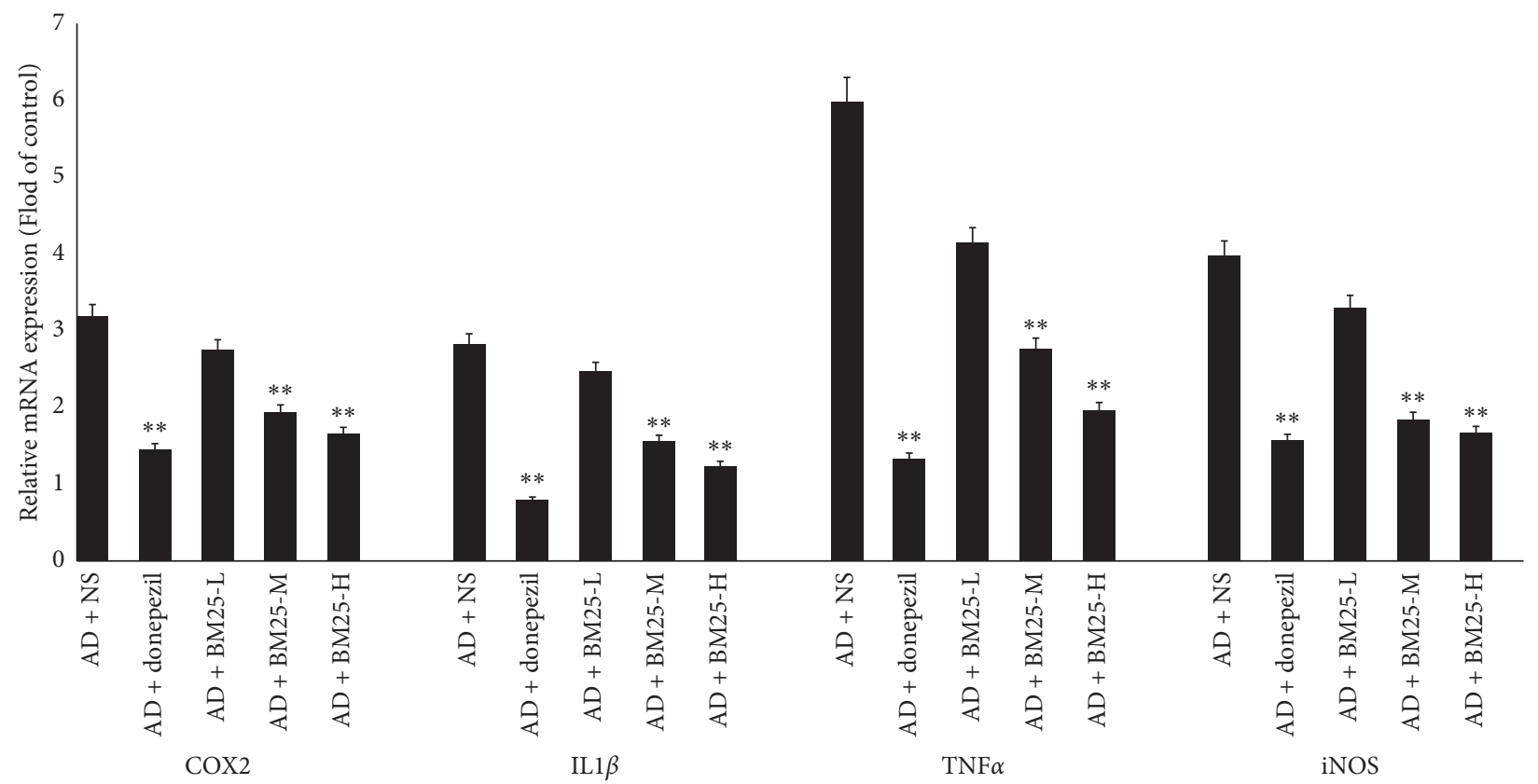

FIgURE 7: The expression levels of IL- $1 \beta$, TNF- $\alpha$, COX2, and iNOS mRNAs in brain tissues in AD + NS, AD + donepezil, and AD + BM25 groups. Data are expressed as the mean \pm standard error of the mean (SEM) ( $n=8$ /group). "**” indicates a significant intergroup difference. BM25: Byu d Mar 25; AD: Alzheimer's disease; NS: normal saline.

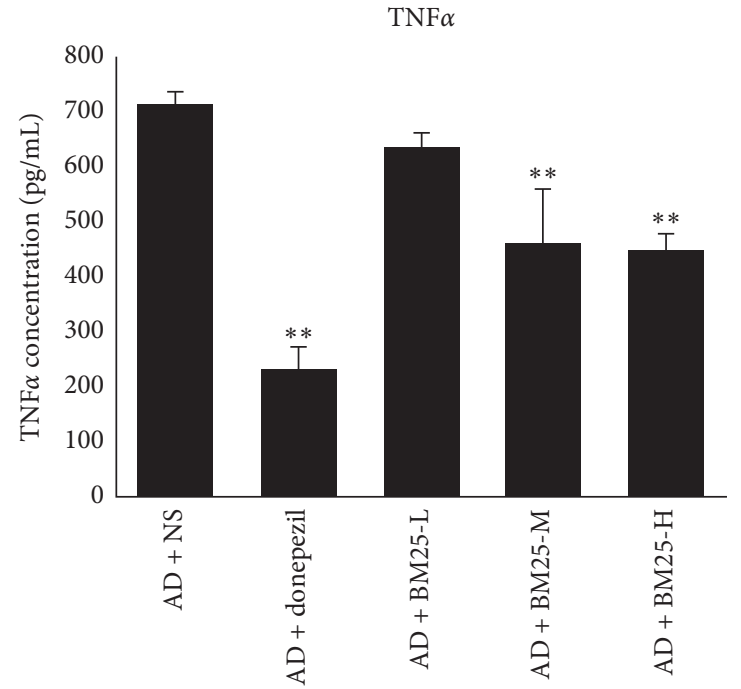

(a)

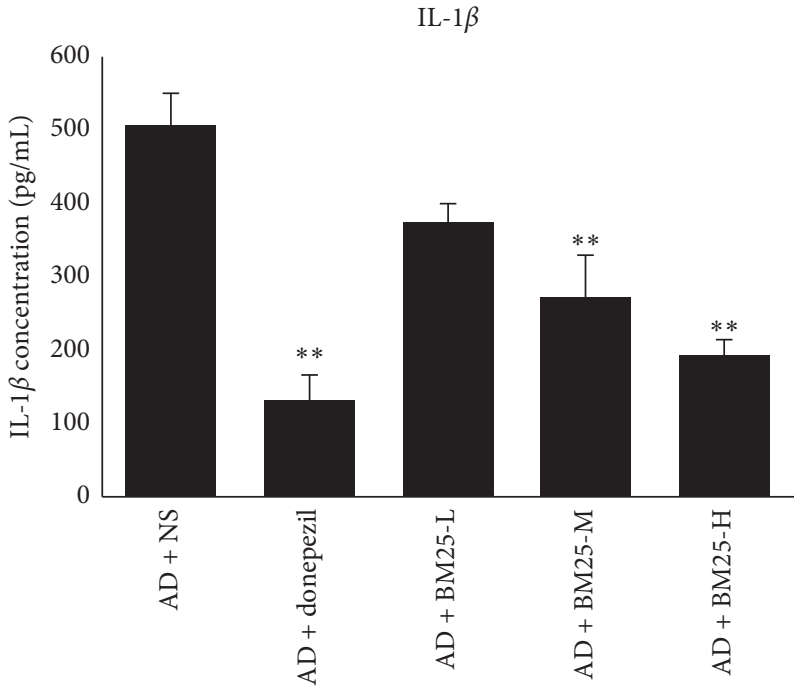

(b)

Figure 8: The expression levels of IL- $1 \beta$ and TNF- $\alpha$ in AD + NS, AD + donepezil, and AD + BM25 groups. (a) IL-1 $\beta$; (b) TNF- $\alpha$. Data are expressed as the mean \pm standard error of the mean (SEM) ( $n=8$ /group). “**” indicates a significant intergroup difference. BM25: Byu $d$ Mar 25; AD: Alzheimer's disease; NS: normal saline.

serine/threonine protein kinase in cells [35]. Normally, MAPK exists in cells in a nonphosphorylated form. Stimulation via recognition of LPS by TLR4 receptors on the surface of microglia can induce the phosphorylation of MAPK and activate the expression of related cytokines and inflammatory mediator genes [36]. Researchers have suggested that, among the three MAPK subfamilies (p38 MAPK, JNK, and ERK), p38 MAPK is most closely related to the inflammatory response [37]. Studies have shown that
LPS promotes the phosphorylation of P38 MAPK in a dosedependent and time-dependent manner, thereby promoting the expression of inflammatory mediators such as TNF- $\alpha$, IL- $1 \beta$, and iNOS. Inhibiting the activation of P38 MAPK can inhibit the production of inflammatory mediators and protect neurons [38-40]. In the present study, the phosphorylation of P38 MAPK was detected by western blotting, and the results showed that BM25 significantly reduced the phosphorylation of P38 MAPK. Therefore, the results of this 
study suggest that BM25 may inhibit the release of inflammatory mediators by inhibiting the P38 MAPK pathway.

However, this study only investigated the effects and preliminary molecular mechanism of inflammatory factor release in an LPS-induced AD mouse model treated with BM25. Cell culture experiments are still lacking at present. Therefore, it will be necessary to carry out cell experiments to better explain the anti-inflammatory and neuroprotective effects of BM25 in neuronal cells.

\section{Conclusion}

BM25 can significantly improve spatial memory, reduce neuronal apoptosis and death, and inhibit the production of $\mathrm{A} \beta$, p-Tau, IL- $1 \beta$, iNOS, COX-2, and TNF- $\alpha$ in an LPSinduced $\mathrm{AD}$ mouse model. Furthermore, BM25 can exert anti-inflammatory and neuroprotective effects by inhibiting the phosphorylation of $\mathrm{I} \kappa \mathrm{B} \alpha$ in the NF- $\kappa \mathrm{B}$ signaling pathway and $\mathrm{p} 38 \mathrm{MAPK}$ in the MAPK signaling pathway.

\section{Data Availability}

The data used to support the findings of this study are included within the article.

\section{Conflicts of Interest}

The authors declare that they have no conflicts of interest.

\section{Acknowledgments}

The research was funded by the Fund for Less Developed Regions of the National Natural Science Foundation of China (81960727), Science and Technology Plan Project of Tibet (XZ201901-GA-01), Foundation of Research Cultivation Program of Tibet University-Growth Project (ZDCZJH18-18, ZDCZJH19-15), Central Support for the Reform and Development of Local Colleges and Universities: Rescue Protection and Construction of Tissue Culture Platform for Endangered and Precious Tibetan Medicinal Material, Science Research Cultivation Project of Medical College in Tibet University (2019XSZX02), Central Support for the Reform and Development of Local Colleges and Universities (00060471), Hunan Natural Science Foundation Youth Program (2019JJ50697), and Changsha Outstanding Innovative Young People Training Scheme (kq2009095).

\section{References}

[1] G. B. Frisoni, M. Boccardi, F. Barkhof et al., "Strategic roadmap for an early diagnosis of Alzheimer's disease based on biomarkers," The Lancet Neurology, vol. 16, no. 8, pp. 661-676, 2017.

[2] D. J. Chambers, J. Sebastian, and D. J. Ahearn, "Parkinson's disease," BJA Education, vol. 17, no. 4, pp. 145-149, 2017.

[3] J. S. Snowden, “The neuropsychology of huntington's disease," Archives of Clinical Neuropsychology, vol. 32, no. 7, pp. 876-887, 2017.

[4] I. Falk and S. Jacobson, "Multiple sclerosis," Neuroimmune Pharmacology, vol. 22, pp. 355-364, 2017.
[5] H. Niu, I. Álvarez-Álvarez, F. Guillén-Grima, and I. Aguinaga-Ontoso, "Prevalence and incidence of Alzheimer's disease in Europe: a meta-analysis," Neurología (English Edition), vol. 32, no. 8, pp. 523-532, 2017.

[6] E. Bagyinszky, V. V. Giau, K. Shim, K. Suk, S. S. A. An, and S. Kim, "Role of inflammatory molecules in the Alzheimer's disease progression and diagnosis," Journal of the Neurological Sciences, vol. 376, pp. 242-254, 2017.

[7] T. P. Kliushnik, L. V. Androsova, N. M. Mikhaylova, I. V. Kolykhalov, S. A. Zozulya, and A. M. Dupin, "Systemic inflammatory markers in age-associated cognitive impairment and Alzheimer's disease," Neuroscience and Behavioral Physiology, vol. 49, no. 10, pp. 352-356, 2019.

[8] M. S. Kim, Y. Kim, and H. Choi, "Transfer of a healthy microbiota reduces amyloid and tau pathology in an Alzheimer's disease animal model," Gut, vol. 69, no. 2, pp. 283-294, Article ID 317431, 2019.

[9] S. P. Raikwar, R. Thangavel, I. Dubova et al., "Targeted gene editing of glia maturation factor in microglia: a novel alzheimer's disease therapeutic target," Molecular Neurobiology, vol. 56, no. 1, pp. 378-393, 2019.

[10] Chinese Pharmacopoeia Committee, The Pharmacopoeia of the People's R epublic of China, China Medical Science Press, Beijing, China, 2015.

[11] W. B. Du, F. K. Huang, Y. D. Luo et al., "Pharmacological research and clinical progress of byur d mar nyerl ngaril bu," World Journal of Integrated Traditional and Western Medicine, vol. 8, no. 5, pp. 537-540, 2013.

[12] C. Yang, P. Li, Y. D. Luo et al., "Effect of 25 odors coral pills on pyramidal cell and the expression of NSE in Hippocampus of D-galactose induced brain aging rats," Natural Product Research and Development, vol. 27, pp. 45-49, 2015.

[13] Y. Liu, X. Song, S. Zheng et al., "Drug-loaded nanoparticles from 'ershiwuwei shanhu' pill induced cellular swelling of $\mathrm{SH}$ SY5Y neuroblastoma cells," Journal of Nanoscience and Nanotechnology, vol. 16, no. 3, pp. 2336-2342, 2016.

[14] X. D. Hu, "A network pharmacology study on mechanism of Tibetan medicine Byur d Mar Nyer 1 Nga Ril Bu against Alzheimer's disease," Chinese Pharmacological Bulletin, vol. 35, no. 1, pp. 128-132, 2019.

[15] L. Tang, L. liu, G. Y. Li, P. C. Jiang, Y. Wang, and J. M. Li, "Expression Profiles of Long non-coding RNAs in Intranasal LPS-mediated Alzheimer's disease model in mice," Biomed. Research International.vol. 2019, Article ID 9642589, 14 pages, 2019.

[16] W. B. Du, L. F. Jia, F. K. Huang et al., "Effect of Byu d Mar 25 on plasma NO and NOS in migraine rats," Pharmacol Clin Chin Mater Med, vol. 29, no. 2, pp. 147-149, 2013.

[17] P. Li, C. Yang, F. K. Huang et al., "Effects of 25 odors coral pills on pyramidal cell and the expression of glial fibrillary acidic protein in Hippocampus of D-galactose induced brain aging rats," Natural Product Research and Development, vol. 26, pp. 606-609, 2014.

[18] C. V. Vorhees and M. T. Williams, "Morris water maze: procedures for assessing spatial and related forms of learning and memory," Nature Protocols, vol. 1, no. 2, pp. 848-858, 2006.

[19] M. Reale, T. Brenner, N. H. Greig et al., "Neuroinflammation, $\mathrm{AD}$, and dementia," International Journal of Alzhmers Disease, vol. 2010, pp. 1340-1347, 2015.

[20] D. L. Krause and M. Norbert, "Neuroinflammation, microglia and implications for anti-inflammatory treatment in alzheimer's disease," International Journal of Alzhmers Disease, vol. 2010, no. 1, pp. 5429-5438, 2010. 
[21] Z. Cai, M. D. Hussain, and L.-J. Yan, "Microglia, neuroinflammation, and beta-amyloid protein in Alzheimer's disease," International Journal of Neuroscience, vol. 124, no. 5, pp. 307-321, 2014.

[22] J. Jiao, B. Xue, L. Zhang et al., "Triptolide inhibits amyloid- $\beta 1-42-$ induced TNF- $\alpha$ and IL- $1 \beta$ production in cultured rat microglia," Journal of Neuroimmunology, vol. 205, no. 1-2, pp. 32-36, 2008.

[23] J. Wang, Y. Jing, L. Song, and Y. Xing, "Neuroprotective effects of $\mathrm{Wnt} / \beta$-catenin signaling pathway against $\mathrm{A} \beta$-induced tau protein over-phosphorylation in PC12 cells," Biochemical and Biophysical Research Communications, vol. 471, no. 4, pp. 628-632, 2016.

[24] Z. F. Jiang, H. C. Huang, X. L. Dai et al., "Cu(II) attenuates oligomeric and fibrillar a $\beta$-induced activation of BV-2 microglia cells," Alzhmers \& Dementia, vol. 6, no. 4, 2010.

[25] D. Nayak, Y. Huo, W. X. T. Kwang et al., "Sphingosine kinase 1 regulates the expression of proinflammatory cytokines and nitric oxide in activated microglia," Neuroscience, vol. 166, no. 1, pp. 132-144, 2010.

[26] N. Liu, Y. Zhuang, Z. Zhou, J. Zhao, Q. Chen, and J. Zheng, "NF- $\kappa \mathrm{B}$ dependent up-regulation of TRPC6 by $\mathrm{A} \beta$ in BV-2 microglia cells increases COX-2 expression and contributes to hippocampus neuron damage," Neuroscience Letters, vol. 651, pp. 1-8, 2017.

[27] Y. Y. Chen, L. P. Cai, H. Wang et al., "The influence of cerebrospinal fluid contained drugs of re-suscitation with aromatics to the expression of aquaporin-4mRNA of brain astrocyte," Modern Journal of Integrated Traditional Chinese and Western Medicine, vol. 17, pp. 1783-1786, 2008.

[28] J. F. Shi, B. A. Zhang, Y. J. Jia et al., "Protective effect of musk extract on rat's cerebral corti-cal neurons with inflammatory injury," Chinese Journal of Integrative Medicine, vol. 30, pp. 625-629, 2010.

[29] L. V. Madrid, C.-Y. Wang, D. C. Guttridge, A. J. G. Schottelius, A. S. Baldwin, and M. W. Mayo, "Akt suppresses apoptosis by stimulating the transactivation potential of the RelA/p65 subunit of NF- $\kappa \mathrm{B}$," Molecular and Cellular Biology, vol. 20, no. 5, pp. 1626-1638, 2000.

[30] L. Liu, X. Li, Y. Wang et al., "Impacts of mild hypothermia on LPS-mediated TLR4/NF- $\kappa$ B signaling pathway in microglia," Journal of Biosciences and Medicines, vol. 07, no. 02, pp. 86-97, 2019.

[31] D. U. Ferreiro and E. A. Komives, "Molecular mechanisms of system control of NF- $\kappa \mathrm{B}$ signaling by $\mathrm{I} \kappa \mathrm{B} \alpha$," Biochemistry, vol. 49, no. 8, pp. 1560-1567, 2009.

[32] J. J. Haddad, "Redox regulation of pro-inflammatory cytokines and $\mathrm{I} \kappa \mathrm{B}-\alpha / \mathrm{NF}-\kappa \mathrm{B}$ nuclear translocation and activation," Biochemical and Biophysical Research Communications, vol. 296, no. 4, pp. 847-856, 2002.

[33] M. Youssef, A. Ibrahim, K. Akashi, and M. S. Hossain, "PUFA-Plasmalogens attenuate the LPS-induced nitric oxide production by inhibiting the NF-kB, p38 MAPK and JNK pathways in microglial cells," Neuroscience, vol. 15, no. 397, pp. 18-30, 2018.

[34] T. Li, Z. Feng, S. Jia et al., "Daintain/AIF-1 promotes breast cancer cell migration by up-regulated TNF- $\alpha$ via activate $\mathrm{p} 38$ MAPK signaling pathway," Breast Cancer Research and Treatment, vol. 131, no. 3, pp. 891-898, 2012.

[35] J. Cuschieri and R. V. Maier, "Mitogen-activated protein kinase (MAPK)," Critical Care Medicine, vol. 33, no. 12, pp. 417-419, 2005.

[36] C. Svensson, K. Part, K. Künnis-Beres, M. Kaldmäe, S. Z. Fernaeus, and T. Land, "Pro-survival effects of JNK and p38 MAPK pathways in LPS-induced activation of BV-2 cells," Biochemical and Biophysical Research Communications, vol. 406, no. 3, pp. 488-492, 2011.

[37] M. Koistinaho and J. Koistinaho, "Role of p38 and p44/42 mitogen-activated protein kinases in microglia," Glia, vol. 40, no. 2, pp. 175-183, 2002.

[38] N. R. Bhat, P. Zhang, J. C. Lee, and E. L. Hogan, "Extracellular signal-regulated kinase and p38 subgroups of mitogen-activated protein kinases regulate inducible nitric oxide synthase and tumor necrosis factor- $\alpha$ gene expression in endotoxin-stimulated primary glial cultures," The Journal of Neuroscience, vol. 18, no. 5, pp. 1633-1641, 1998.

[39] J. C. Lee, J. T. Laydon, P. C. McDonnell et al., "A protein kinase involved in the regulation of inflammatory cytokine biosynthesis," Nature, vol. 372, no. 6508, pp. 739-746, 1994.

[40] S. C. Lee, "Cytokine production by human fetal microglia and astrocytes. Differential induction by lipopolysaccharide and IL- beta," Journal of Immunology, vol. 150, no. 7, pp. 26592667, 1993. 